\title{
APORTES CRÍTICOS SOBRE EL DERECHO INTERNACIONAL PENAL Y LA CPI
}

\author{
JAVIER ECHAIDE
}

Artículo de reflexión

DOI: http://dx.doi.org/10.15425/redepub.33.2014.11

Universidad de los Andes

Facultad de Derecho

Revista de Derecho Público N. ${ }^{\circ} 33$

Julio - Diciembre de 2014. ISSN 1909-7778 


\section{Aportes críticos sobre el derecho internacional penal y la CPI}

\section{Resumen}

Este artículo resume algunos aportes críticos en lo referente al derecho internacional penal, especialmente en lo que concierne a la Corte Penal Internacional (CPI), analizando sus avances más actuales a partir de la Conferencia de Kampala (2010) y revisando materias pendientes a la luz de los denominados "crímenes de masa", cuestión de complejo tratamiento para el derecho internacional.

Palabras clave: derecho internacional penal, Corte Penal Internacional, Estatuto de Roma, derecho internacional público, crímenes de masa.

\section{Critical inputs on international criminal law and the ICC}

\section{Abstract}

This article summarizes some critical input in relation to international criminal law, especially in regard to the International Criminal Court (ICC), analyzing their current progress from the Kampala Conference (2010) and revised pending issues in light of "crimes of mass", something complex for international law regulation.

Keywords: International criminal law, International Criminal Court, Rome Statute, International law, mass crimes.

\section{Contribuições críticas sobre o direito internacional penal e a CPI}

\section{Resumo}

Este artigo resume algumas contribuições críticas no que se refere ao direito internacional penal, especialmente no que concerne à Corte Penal Internacional (CPI), analisando seus avanços mais atuais a partir da Conferência de Kampala (2010) e revisando matérias pendentes à luz dos denominados "crimes de massa", questão de complexo tratamento para o direito internacional.

Palavras-chave: direito internacional penal, Corte Penal Internacional, Estatuto de Roma, direito internacional público, crimes de massa. 


\title{
Aportes críticos sobre el derecho internacional penal y la $\mathrm{CPI}^{*}$
}

\author{
Javier Echaide ${ }^{* *}$
}

\section{SUMARIO}

Introducción - I. UNA RELACIÓN TURBULENTA: LOS EE. UU. Y LA CPI - A. Los acuerdos bilaterales de inmunidad - B. La Ley de Protección para los Miembros del Servicio Americano (ASPA) - C. La Enmienda Nethercutt y las suspensiones de financiamiento a los miembros de la CPI - D. Resoluciones de inmunidad ante la CPI del Consejo de Seguridad - II. EL CRIMEN DE AGRESIÓN - A. La Resolución 6 y la definición del crimen de agresión - III. DE LA APLICACIÓN DE ALGUNOS PRINCIPIOS DE DERECHO - IV. SOBRE LOS DELITOS Y CRÍMENES INTERNACIONALES Y EXIMICIONES PARTICULARES - V. EL PROCESO DE ENMIENDAS AL ESTATUTO DE ROMA: LA CONFERENCIA DE KAMPALA (2010) - VI. ALGUNOS CASOS DE POSIBLE APLICACIÓN DEL ESTATUTO DE LA CPI - A. Posible aplicación del estoppel para Estados no miembros de la cPI a raíz de la situación en Libia (2011) - VII. A MODO DE CONCLUSIÓN: ALGUNOS APORTES TEÓRICOS CRíTICOS SOBRE LOS CRÍMENES DE MASA - Referencias.

* Cómo citar este artículo: Echaide, J. (Diciembre, 2014). Aportes críticos sobre el derecho internacional penal y la cPI. Revista de Derecho Público, 33. Universidad de los Andes (Colombia).

** Abogado (Universidad de Buenos Aires, UBA). Doctor en Derecho (UBA) especializado en Derecho Internacional Público. Magíster en Relaciones Internacionales (c) (UBA). Investigador adscripto del Inst. Ambrosio Gioja (Fac. Derecho, UBA). Miembro del Instituto de Relaciones Internacionales e Integración -IRINI- (Fac. Derecho, UNLZ). Docente de Derecho Internacional Público (UBA y UNLZ). Correos: jechaide@hotmail.com o javierechaide@derecho. uba.ar 
Introducción

No debemos dudar de que la punibilidad penal a nivel internacional de los delitos de lesa humanidad sea un avance de altísima consideración en lo que concierne al desarrollo progresivo del derecho internacional público.

La creación de un esquema jurídico que persiga individualmente a genocidas y autores de otros crímenes igualmente aberrantes ha sido un largo y arduo proceso de más de cincuenta años de construcción, que no merece sino nuestro reconocimiento consciente por el logro al que se ha llegado. Pero lo dicho tampoco debe colocarnos en la falsa posición de estar a riesgo de perderlo todo ante la más mínima crítica: el miedo es la mayor de las trabas para la superación de los obstáculos que impidan progresos en la adquisición de cada vez mayores derechos que nos lleven a la plena realización de hombres y mujeres como tales.

Es por eso que mantenemos el análisis crítico, incluso de instituciones y acuerdos internacionales que recogen los elogios políticamente más correctos. Por ello creemos que es necesario aclarar desde dónde es que analizamos críticamente estos documentos: una postura acorde con la progresividad de los derechos sociales y con la defensa irrestricta de los derechos humanos.

Es relativamente reciente la vigencia del Estatuto de Roma, que creó la Corte Penal Internacional (CPI), al menos para los términos que generalmente se suelen manejar en el derecho interna- cional. Sin embargo, se esperaba que su entrada en vigor -ocurrida el $1^{\circ}$ de julio de 2002-resultara algo mucho más costoso de lo que fue en realidad, sino imposible que ocurriera.

La firma del Estatuto de Roma se realizó en 1998 y para su entrada en vigor se requerían sesenta instrumentos de ratificación depositados que manifestasen la voluntad de los Estados en obligarse, algo que constituía una exigencia alta. Si se tiene en cuenta que la negociación de este tratado demoró cincuenta años -contados desde la adopción de la Convención para la Prevención y Sanción del Delito de Genocidio en 1948-, el requerimiento de sesenta ratificaciones era, sin dudas, en concepto de algunos juristas un obstáculo para su efectiva vigencia. Otros opinaban lo contrario: que un alto número de ratificaciones manifestaría un grado de apoyo contundente por parte de la comunidad internacional para la entrada en vigor del acuerdo y la efectiva fundación de la cP..

Sin embargo, este gran obstáculo no resultó tal pues en tan solo cuatro años el Estatuto de Roma entró en vigor cumpliendo con las sesenta ratificaciones exigidas por el art. 126, a pesar de las objeciones de otros Estados importantes que restaron su apoyo. Tal es el caso de Rusia, China, India, Israel, Cuba, Irak y Estados Unidos, siendo este último el caso más polémico.

Argentina ingresó a la cPI el 8 de febrero de 2001, fecha en que depositó en poder del Secretario General de Naciones Unidas los instrumentos de ratificación exigidos. Las "relaciones carnales" con los EE. UU. durante los 90 volvie- 
ron urticantes las posibilidades de ratificación del Estatuto en aquellos años, pero el final del menemismo abrió la puerta para un cambio en este sentido -si bien muchas de las políticas neoliberales no sufrieron alteraciones hasta la crisis de diciembre de ese año-, a diferencia de nuestro principal socio regional que por largo tiempo impulsó la creación de este organismo internacional. De hecho, el liderazgo brasileño sobre el tema puede también reflejarse dentro del ámbito de la Unión Sudamericana de Naciones (Unasur), ya que de los Estados miembros de dicho bloque solo dos no forman parte de la CPI: Chile y Surinam; Colombia ingresó el 11 de marzo de 2003. Actualmente 122 países se han obligado con el Estatuto de Roma. ${ }^{1}$

En este trabajo abordamos los aspectos más polémicos del mencionado Estatuto y de la cPI, iniciando por la conflictiva relación que mantiene Estados Unidos con esta organización, y las distintas medidas que esta potencia mundial ha tomado para evitar no solo que el tratado en cuestión pueda serle aplicable, sino además para restarle peso político al citado organismo internacional.

Luego encaramos la complejidad que representó el crimen de agresión, un delito incluido en 1998 en el Estatuto de la Corte pero que no fue definido en ese entonces, dejándolo por ende como un tipo penal abierto con el consiguiente riesgo de que la cPI se viera políticamente atada

1 La lista de Estados Partes de la CPI puede verse en: http://www.icccpi.int/en_menus/asp/states\%20parties/Pages/the $\% 20$ states $\% 20$ parties $\% 20$ to $\% 20$ the $\% 20$ rome $\% 20$ statute.aspx\#. para poder juzgar acciones que calificaran dentro de dicho crimen.

Seguimos con la aplicación de algunos principios generales de derecho en el ámbito internacional, lo cual plantea ciertas dificultades a raíz de que el derecho internacional público se ha encontrado varias veces en la situación de tener que juzgar a quienes han cometido crímenes contra la humanidad sin contar con una ley que reprima los actos aberrantes por ellos cometidos, y aunque se obró con base en el derecho posterior al acto, hay algo que quiebra, por ejemplo, los principios más elementales del derecho penal.

Analizaremos más en detalle algunos puntos problemáticos del Estatuto de Roma sobre todo en lo que atañe a la supuesta independencia en los hechos, no simplemente en la norma-de la Fiscalía de la cPI y el posible rol que el Consejo de Seguridad de la onu posee para controlarla, con lo cual se pone en riesgo la potestad del Fiscal para efectuar investigaciones sobre casos que pudieran resultar "políticamente inconvenientes". Del mismo modo abordaremos algunos crímenes omitidos por el Estatuto de Roma y que podrían haber sido considerados al momento de determinar los tipos penales de competencia de la Corte.

Finalmente, avanzaremos sobre el proceso de reformas del Estatuto de la cPI, iniciado en el 2010 en una conferencia plenipotenciaria de todos los Estados Parte para ir sobre puntos para nada menores: la definición de agresión, la eliminación de la excepción a ser investiga- 
do que detalla el art. 124 del Estatuto, el propio proceso de evaluación del funcionamiento de la Corte, entre otros.

\section{UNA RELACIÓN TURBULENTA: LOS ESTADOS UNIDOS Y LA CPI}

El 17 de julio de 1998, la Conferencia Diplomática de Plenipotenciarios de las Naciones Unidas sobre el Establecimiento de una corte penal internacional, reunida en Roma, Italia, aprobó el "Estatuto de Roma de la Corte Penal Internacional". La votación sobre si se debía proceder o no a la firma del Estatuto preparado por la Conferencia fue de 120 votos a favor, 7 en contra y 21 abstenciones. Con ello se cerró la etapa de negociaciones y se adoptó el texto. Estados Unidos votó en contra de la aprobación definitiva del Estatuto.

Posteriormente, el entonces Presidente de los EE. UU., el demócrata Bill Clinton, lo firmó el 31 de diciembre de 2000, último día en que estaba abierto a la firma en la sede de las Naciones Unidas. En una declaración emitida ese mismo día, Clinton, frente a la pregunta sobre una posible ratificación norteamericana, dijo: "No lo haré, y no recomendamos a mi sucesor presentar el Acuerdo al Senado para su tratamiento y consentimiento hasta que nuestras preocupaciones fundamentales se cumplan" (Departamento de Estado de los EE. UU., 2003). Con ello se refería a que las "deficiencias" del texto no habían tenido una reparación que satisficiera el interés de los Estados Unidos.
Cinco meses después, y antes de la entrada en vigor del documento, el republicano George W. Bush "anuló" la firma de Clinton mediante una carta fechada el 6 de mayo de 2002 y dirigida a Koffi Annan, por aquel entonces Secretario General de la onu. Desde 2002, el gobierno de los Estados Unidos lleva a cabo una campaña multifacética contra la cPI, aduciendo que esta puede comenzar enjuiciamientos motivados políticamente en contra de ciudadanos estadounidenses.

Este acto de anulación de la firma que autenticaba el texto constituyó un escándalo no lo suficientemente atendido por la opinión pública internacional, ya que de acuerdo con los arts. 42 y 43 de la Convención de Viena de 1969 sobre Derecho de los Tratados es completamente válida la voluntad de un Estado de retirarse o de proceder a la denuncia de un acuerdo internacional al que se haya comprometido u obligado con su firma a título de ratificación, adhesión u otro tipo de acto de igual tenor. Lo que la administración de Bush (h) transmitió a la comunidad internacional al retirar la firma es que llevaría el texto al Congreso Nacional para que lo revisase y eventualmente le dijera al poder ejecutivo que podía ratificarlo. Si bien esa firma no comprometía a los EE. UU. con ninguna de las obligaciones expresadas en el Estatuto, el gobierno la retiró so pretexto de que pudiera implicar "posibles futuras interpretaciones" de un compromiso norteamericano para con la jurisdicción de la cP.

Con esto, podría pensarse que los EE. UU. participaron en las negociaciones con el fin de llegar a posiciones y cláusulas que coartaran la total y completa independencia del Tribunal tanto 
de los Estados como del Consejo de Seguridad de la onu -tema que mencionaremos más adelante- pero jamás accedería a obligarse con el tratado, mientras el resto de los Estados procedieron a la ratificación del Estatuto de Roma y con ello a ser miembros plenos de la cPI, sometiéndose a la jurisdicción de esta. Si así fuera, tal acto no podría compararse más que con la carencia de buena fe en las negociaciones, uno de los principios generales básicos del derecho internacional público.

\section{A. Los acuerdos bilaterales de inmunidad}

Pero el tema no quedó simplemente en ese episodio. Los esfuerzos del gobierno de los EE. UU. para socavar el poder de la cPI no han sido pocos ni se limitan solamente a su negativa en adherir al Estatuto de Roma, sino que incluyen, entre otras medidas, los Ilamados acuerdos bilaterales de inmunidad (ABI).

A partir del año 2001 la administración Bush (h) consultó con diversos Estados alrededor del mundo la posible firma de tratados bilaterales que otorguen inmunidad a las tropas norteamericanas en actividad fuera del suelo estadounidense, como vía para poder excluir a sus ciudadanos y a su personal militar de la jurisdicción de la Corte, basándose en una interpretación del art. 98 del Estatuto de Roma:

Art. 98. Cooperación con respecto a la renuncia a la inmunidad y consentimiento a la entrega.

1. La Corte no dará curso a una solicitud de entrega o de asistencia en virtud de la cual el
Estado requerido deba actuar en forma incompatible con las obligaciones que le imponga el derecho internacional con respecto a la inmunidad de un Estado o la inmunidad diplomática de una persona o un bien de un tercer Estado, salvo que la Corte obtenga anteriormente la cooperación de ese tercer Estado para la renuncia a la inmunidad.

2. La Corte no dará curso a una solicitud de entrega en virtud de la cual el Estado requerido deba actuar en forma incompatible con las obligaciones que le imponga un acuerdo internacional conforme al cual se requiera el consentimiento del Estado que envíe para entregar a la Corte a una persona sujeta a la jurisdicción de ese Estado, a menos que esta obtenga primero la cooperación del Estado que envíe para que dé su consentimiento a la entrega.

Estas cuestiones de cooperación internacional suelen estar atadas a otros temas. La negativa de un Estado a cooperar con la CPI puede tener repercusiones diplomáticas a nivel internacional dentro del esquema de la onu; y la renuencia a firmar un ABI con los EE. UU. ha llevado a denegar asistencia financiera por parte del país norteamericano a otro, ${ }^{2}$ como le sucedió a Uruguay en 2004, para citar un ejemplo concreto (Falca y Martínez Soto, 2004).

Estos acuerdos prohíben la entrega a la cPI de aquellas personas que pudieran estar implicadas en actos de genocidio o crímenes de lesa humanidad, incluyendo a antiguos y a actuales funcionarios de gobierno, personal militar, empleados de los EE. UU. (incluso contratados) y

2 Ver también la Enmienda Nethercutt comentada en este artículo. 
ciudadanos comunes. Dichos acuerdos, que en muchos casos son recíprocos, no incluyen siquiera -y es lo más grave- la obligación de los EE. UU. de investigar o enjuiciar a esas personas bajo la jurisdicción norteamericana, con lo que no se otorga garantía alguna para evitar que tales actos puedan quedar impunes.

\section{B. La Ley de Protección para los Miembros del Servicio Americano (ASPA)}

Como complemento de los ABI, el Congreso de Ios EE. UU. sancionó en agosto de 2002 la American Service-Members' Protection Act (Ley de Protección para los Miembros del Servicio Americano), ASPA por sus siglas en inglés.

Esta ley federal fue presentada por Jesse Helms, senador por Carolina del Norte, miembro ultraconservador del Partido Republicano y asesor del expresidente Ronald Reagan durante su administración en los 80. Según el Departamento de Estado, Ia ASPA es como una enmienda a la Ley de Autorización de Defensa Nacional norteamericana que fuera aprobada en agosto de 2002 por el Congreso, y cuyo propósito declarado es "proteger al personal militar de los Estados y otros funcionarios elegidos y designados del gobierno de Estados Unidos contra enjuiciamiento penal por un tribunal penal internacional para el que los Estados Unidos no es parte" (Departamento de Estado, 2003).

La ASPA contiene disposiciones que restringen la cooperación de los EE. UU. con la CPI y hacen que su apoyo a las misiones para el manteni- miento de la paz se ponga en duda, dado que se sujeta a una garantía de impunidad para los funcionarios estadounidenses que pudieran ser llamados por la Corte ante posibles violaciones al Estatuto de Roma. Esta ley incluso contempla un permiso al presidente de los EE. UU. para utilizar "cualquier medio necesario" con el fin de liberar a ciudadanos estadounidenses y de países aliados de la custodia de la CPI en la ciudad de La Haya (por ello se conoce a esta autorización como Ley de Invasión a La Haya).

EE. UU. no solo ha sido el principal crítico del establecimiento de la Corte Penal Internacional, sino que el 2 de agosto de 2002, a solo días de la entrada en vigor del Estatuto de Roma, el Congreso norteamericano aprobó la mencionada ley federal, acto que tuvo el claro objetivo de debilitarla: prohíbe a los gobiernos y a los organismos federales, estatales y locales estadounidenses -incluidos los tribunales y los organismos encargados de hacer cumplir la ley-asistir a la Corte en el cumplimiento de sus funciones; prohíbe a los gobiernos federales, estatales y locales, y a los organismos (incluidos los tribunales y demás entes de aplicación de la ley) la entrega de cualquier persona de Ios EE. UU. a la cPl; y -lo más grave- prohíbe a los agentes de dicho tribunal llevar a cabo investigaciones en territorio de los EE. UU., algo que veremos más adelante; prohíbe la ayuda militar de Estados Unidos a los países que son parte de la cPI; y autoriza al presidente de los Estados Unidos a utilizar "todos los medios necesarios y adecuados para lograr la liberación de cualquier persona [estadounidense o de un aliado] detenida o encarcelada, en nombre de, o a solicitud de 
la Corte Penal Internacional" (Departamento de Estado, 2003).

Esta norma norteamericana pretende "exceptuar" de toda responsabilidad penal -incluyendo la que podría invocarse bajo jurisdicción del Estatuto- a las fuerzas estadounidenses en servicio de la imprescriptibilidad y la jurisdicción universal que el Estatuto establece y que la costumbre internacional reconoce en cuanto a los delitos de lesa humanidad y violación de derechos humanos, que incluso hoy constituyen norma jus cogens dentro del derecho internacional. Con esta amplísima interpretación, en caso de encarcelamiento por la cPI de algún miembro de las fuerzas armadas norteamericanas o de algún aliado de ellas, los EE. UU. pueden intervenir directa y militarmente la sede de la CPI y proceder a su liberación por la fuerza, lo cual resulta un escándalo mayúsculo a ojos de la comunidad internacional.

Este tipo de medidas no solo pueden entorpecer la labor de la cPI, sino que además van en abierta contraposición de la voluntad de la comunidad internacional al establecer un organismo internacional que persiga a quienes cometen crímenes aberrantes contra la humanidad, aplicando la normativa hoy existente en la materia.

Luego de la aprobación del Estatuto de Roma (1998) y previo a su entrada en vigor (2002), la misión negociadora de los EE. UU., encabezada por el embajador David Scheffer -abogado y diplomático especializado en temas de derecho penal internacional y crímenes de guerra durante la administración Clinton-, declaró ante el
Congreso norteamericano que dicho país no podría firmarlo debido a un problema de raíz: que algunos objetivos fundamentales de la negociación norteamericana no se habían logrado. Sus palabras precisas fueron: "Nos quedamos con consecuencias que no sirven a la causa de la justicia internacional" (Departamento de Estado, 2003), al menos en los términos en que los EE. UU. la entienden.

El embajador Scheffer llegó a decirle al Congreso:

Las fuerzas multinacionales de paz que operan en un país que se ha unido al Tratado, pueden estar expuestas a la competencia de la Corte, incluso si el país que aporta al mantenimiento de la paz [es decir el Estado que aporta las tropas] no se ha sumado al tratado. De este modo, el Tratado pretende establecer un acuerdo por el cual las fuerzas armadas de los Estados que operan en el extranjero podrían ser procesadas por el Tribunal Internacional, aun cuando los Estados Unidos no hayan convenido en obligarse por el Tratado. Esto no sólo es contrario a los principios más fundamentales del derecho de los tratados, [sino que] podría inhibir la capacidad de los Estados Unidos de utilizar sus fuerzas armadas para cumplir con las obligaciones de sus alianzas ${ }^{3}$ y participar en operaciones multinacionales, incluidas las intervenciones humanitarias para salvar vidas de civiles. Otros contribuyentes a las operaciones de mantenimiento de la paz tendrán una exposición similar (Departamento de Estado, 2003).

Según la postura oficial norteamericana, a cualquier estadounidense procesado por la CPI -en

Scheffer hace aquí una referencia implícita a la Organización del Tratado del Atlántico Norte (OTAN), por ejemplo. 
el marco del Estatuto de Roma- se le niegan las protecciones de procedimiento a que tiene derecho en virtud de la Carta de Derechos de la Constitución de Estados Unidos, tales como el derecho a un juicio con jurado. Si bien esto es cierto, también hay que considerar cómo es la recepción que, en forma consuetudinaria, los juristas aplican respecto de los principios generales de derecho reconocidos como fuente formal del derecho internacional público según el art. 38 del Estatuto de la Corte Internacional de Justicia (CIJ), anexo a la Carta de la onu -que vale aclarar, los EE. UU. sí han ratificado-.

El art. 38 del Estatuto de la cls enumera fuentes formales del derecho internacional público, y una de ellas son los principios generales de derecho "reconocidos por las naciones civilizadas". Este punto del mencionado artículo hace referencia no a los principios del derecho internacional, sino a los principios de derecho interno que sean comunes dentro de la diversidad de Estados que conforman la comunidad internacional. El jurista, en caso de tener que resolver una cuestión, deberá abstraer los principios comunes de cada derecho interno y descartar los no comunes, para así conformar una gama de principios generales que son efectivamente compartidos por toda la comunidad internacional, evitando así aplicar determinado sistema jurídico nacional.

En el tema que discutimos aquí, los EE. UU. alegan que a los procesados por la cPI se les deniega el juicio por jurados, y es cierto. Pero el Departamento de Estado bien debe saber que el criterio a aplicar a alguien que es procesado por la comunidad internacional no es el emanado del derecho interno norteamericano sino el del derecho internacional público, surgido de la voluntad de la comunidad internacional, a la que sin dudas EE. UU. pertenece. En tal caso, el juicio por jurados no es en absoluto un principio receptado por la comunidad de Estados a nivel internacional, siquiera en forma más o menos amplia; motivo por el cual, el argumento de reclamar la aplicación de un derecho propio del derecho interno estadounidense a un procesado bajo jurisdicción internacional -valga decir de la CPI - es algo, por lo menos, bastante discutible.

Empero, la postura oficial reclama abiertamente que:

Los miembros de las Fuerzas Armadas de los Estados Unidos deben estar libres de riesgo del procesamiento por la Corte Penal Internacional, especialmente cuando están estacionados o desplegados en todo el mundo para proteger los intereses vitales nacionales de los Estados Unidos. El Gobierno de Estados Unidos tiene la obligación de proteger a los miembros de sus Fuerzas Armadas, en la medida de lo posible, en contra de los procesos penales llevados a cabo por la cPI (Departamento de Estado, 2003).

Sobran mayores comentarios...

No obstante todo lo dicho, EE. UU. entiende que es un principio fundamental del derecho internacional que un tratado sea vinculante solo para sus partes y que no genere obligaciones para los que no sean partes sin su consentimiento en obligarse: ergo, no reconoce para este caso 
la existencia del pacta tertis en el derecho internacional. Al no ser EE. UU. un Estado parte en el Estatuto de Roma, no está obligado en absoluto por este, incluyendo los deberes de cooperación con el Tribunal. Con ello, Ios Estados Unidos no reconocen la jurisdicción de la CPI sobre ningún nacional estadounidense ni sobre su territorio, como tampoco se sienten siquiera obligados a cooperar de manera alguna con la Corte.

\section{La Enmienda Nethercutt y las suspensiones de financiamiento a miembros de la CPI}

El 15 de julio de 2005, la Casa de los Representantes (Cámara Baja del Congreso de EE. UU.) adjuntó una enmienda "anti-CP”" a la Foreign Operations appropriations Bill. Fue presentada por el representante George Nethercutt --político republicano del Estado de Washington-, y suspende la ayuda del Economic Support Fund (ESF) a todos los países que han ratificado el tratado de la cPI y que no hayan firmado el ABI con los Estados Unidos. Conocida como la Enmienda Nethercutt, fue aprobada por el Senado y luego promulgada por el presidente Bush (h) el 8 de diciembre de 2004.

Así, el 2 de octubre de 2006, el presidente Bush (h) dispensó la prohibición de otorgar financiamientos bajo el International Military and Education Training (IMET) a 21 Estados Partes de la CPI que habían previamente rechazado la firma de un ABI (Coalisión por la Corte Penal Internacional -cCPI, s. f. a). Adicionalmente, el 17 de octubre de 2006, firmó la Defense Authorization Act para ese año fiscal y reinstauró los financia- mientos IMET rechazados bajo las disposiciones del ASPA. Poco después, el 28 de noviembre, eximió las prohibiciones de financiamiento del ESF a 14 de los Estados Partes que habían perdido dicha asistencia en cumplimiento de la Enmienda Nethercutt.

Esto, sin embargo, no contempló la reactivación de los fondos de financiamiento militar para países extranjeros (FMF) que fueron amenazados bajo el ASPA o de los fondos de ayuda económica del ESF amenazados con la Enmienda Nethercutt. Tres países que también recibían financiamiento del ESF (Irlanda, Brasil y Venezuela) no fueron perdonados de las prohibiciones de la Enmienda Nethercutt, motivo por el cual la asistencia del ESF por aproximadamente US\$ 15 millones aún sigue fuertemente condicionada.

Como sabemos, la decisión de otorgar o no financiamientos es una potestad del Estado que los ofrece. Sin embargo, el que se hallen directamente condicionados a la firma o no de los ABI, esto es, a la "garantía de impunidad" a las fuerzas norteamericanas en servicio, es algo que va más allá de la sola decisión estatal y constituye un fuerte condicionante para doblegar la voluntad soberana de los Estados que se ven forzados a firmar estos "acuerdos de impunidad" para poder ser beneficiarios de los fondos prometidos.

Más allá de los argumentos jurídicos, la aplicación contante y sonante de la realpolitik es una fuerte presión que pesa sobre las voluntades políticas de turno. 


\section{Resoluciones de inmunidad ante la CPI del Consejo de Seguridad}

Por último, y como parte de la campaña norteamericana para lograr una inmunidad total para sus tropas de mantenimiento de paz, EE. UU. abogó por la adopción de la Resolución 1422 del Consejo de Seguridad de la onu (aprobada en julio de 2002 y renovada por la Resolución 1487 en junio de 2003), por medio de la cual se otorgó inmunidad al personal de Estados no partes de la cP involucrados en las misiones establecidas o autorizadas por las Naciones Unidas, por un período renovable de doce meses. A pesar de los esfuerzos de EE. UU. por renovar esta resolución nuevamente en 2004, debió retirarla al no poder asegurar los votos necesarios en el Consejo de Seguridad para su aprobación.

La asunción del demócrata Barack Obama a la presidencia norteamericana despertó gran fervor entre los defensores de los derechos humanos y sectores progresistas que veían en él la posibilidad de virar la política exterior de Bush y asumir un mayor compromiso con el multilateralismo dentro de la agenda internacional. Pero tras varios años de mandato es dudoso que la administración de Barack Obama suscriba el Estatuto de Roma. Las razones radican primeramente en la hostilidad del Congreso hacia su gestión, más aún tras la sanción de la nueva ley sobre el sistema de salud que significó una victoria pírrica para Obama. El sector militar también es un grupo de presión con mucho poder dentro de los EE. UU. y seguramente se opondrá, tal como lo ha hecho hasta ahora. Y, por último, el riesgo que significa el permitir la juris- dicción universal y extraterritorial sobre tropas en combate del Estado que más fuerzas tiene en el extranjero en comparación con cualquier otro país en el mundo -lo cual también es un dato del liderazgo de EE. UU. para actuar como gendarme de la seguridad internacional-. Esta sumatoria hace que el solo hecho de pensar en una firma del Estatuto signifique costos políticos muy altos que no cualquier administración podrá asumir, incluso la de Obama.

\section{EL CRIMEN DE AGRESIÓN}

Como vemos, la aplicación del Estatuto de Roma no ha estado exenta de dificultades, que incluyen a jugadores de peso dentro de la arena global. Pero también están las críticas de otros actores internacionales y que tienen asidero. Una de ellas es el establecimiento de tipos penales abiertos dentro de los delitos reconocidos en el Estatuto.

Amplia es la doctrina en derecho penal sobre los problemas que conllevan los tipos penales abiertos, esto es, la definición indeterminada de una conducta que implica una violación a la norma establecida y que es imputable a una persona.

Al momento de establecerse la cPI el crimen de agresión no había sido definido, aunque el tipo penal sí estaba contemplado, ya que era uno de los cuatro crímenes que el Estatuto de Roma establecía para la jurisdicción del Tribunal. Esto presentaba un problema serio, dado que no solamente había -y hay- pocos delitos tipificados, sino que uno de ellos no estaba definido 
estrictamente por ser el más polémico para determinar.

El art. 5 del Estatuto de la cPI establece que la Corte solamente podrá actuar sobre cuatro tipos de crímenes específicos: el crimen de genocidio, los crímenes de lesa humanidad, los crímenes de guerra y el crimen de agresión. Mientras que los tres primeros fueron definidos en forma acabada $-\mathrm{y}$ en algunos casos minuciosa-, el crimen de agresión quedó pendiente. El propio art. 5 aclara que: "La Corte ejercerá competencia respecto del crimen de agresión una vez que se apruebe una disposición de conformidad con los artículos 121 y 123 en que se defina el crimen y se enuncien las condiciones en las cuales lo hará. Esa disposición será compatible con las disposiciones pertinentes de la Carta de las Naciones Unidas".

De este modo quedó aplazada la necesaria definición del crimen de agresión, un concepto que siempre ha ocasionado discrepancias dentro de la comunidad internacional debido a los distintos intereses que se ponen en juego al querer tipificar penalmente este delito para perseguir internacionalmente a los individuos responsables de tales actos.

Los mencionados arts. 121 y 123 -sobre enmiendas y revisión del texto del Estatuto, respectivamente- determinaban que cualquier agregado que pueda hacerse al texto autenticado deberá realizarse recién transcurrido el plazo de siete años desde su entrada en vigor. El debate se suscitó entonces entre una posible definición del delito aludiendo a la Resolución
3314 (XXIX) de la Asamblea General de la onu que específicamente definía tal concepto como: "el uso de la fuerza armada de un Estado contra la soberanía, la integridad territorial o la independencia política de otro Estado, o en cualquier forma incompatible con la Carta de las Naciones Unidas...".

No era poca la opinión dentro de la comunidad internacional que se manifestaba contraria a la indefinición de este tipo penal, y que reclamaba aplicar la definición ya adoptada en el seno de la Asamblea General de Naciones Unidas, a la que tanto defensores como críticos de la CPI acordaban respetar.

Sin embargo, el Estatuto de Roma mostraba otro escollo: la imposibilidad de sentenciar aplicando penas por analogía. La inclusión del principio penal nullun crimen sine praevia lege en el art. 22 explícitamente impedía interpretaciones que pudieran ser traídas desde fuera de la norma (es decir del Estatuto), aun cuando ellas contaran con una amplísima aceptación. Por ende, la definición del crimen a ser punido debía ser interpretada de manera estricta y no haciéndose extensiva por analogía.

Con ello, la agresión definida por la Res. 3314 podía constituir un crimen por fuera del texto del Estatuto, aplicable a los efectos del derecho internacional público (es decir imputable a Estados) pero no a los efectos del derecho penal internacional (imputable a los responsables individuales de la toma de decisiones de tales actos). El resultado práctico podía implicar una imputación de responsabilidad internacional con- 
tra un Estado que hubiera cometido el acto de agresión, y de ese manera exigirle algún modo de resarcimiento de los contemplados en el derecho internacional público -como la restitución o la indemnización, ya que difícilmente vemos a la satisfacción como una forma suficiente de resarcirse frente a un crimen de agresión-, pero no podía castigarse penalmente a las personas involucradas en la toma de la decisión política de llevar a cabo ese acto.

Esto pudo resolverse a partir del proceso de enmienda del Estatuto abierto en la Conferencia Internacional de Kampala, en el año 2010, donde se analizó el art. 5 a fin de adoptar una definición sobre el crimen de agresión. Al efecto se convocó a la sesión plenaria de la Asamblea de Estados Miembros del Tribunal, el 11 de junio de 2010. Hasta entonces, la calificación de un acto de agresión era competencia del Consejo de Seguridad de la onu, según la Carta de las Naciones Unidas.

En este sentido la postura oficial de los EE. UU. tenía asidero, ya que la cPI podría, en virtud de la aplicación del art. 5 del Estatuto de Roma, interpretar si un acto constituye o no una agresión y actuar en consecuencia. Para los EE. UU.:

Cualquier acuerdo dentro de la Comisión Preparatoria sobre la definición del crimen de agresión que usurpe las prerrogativas del Consejo de Seguridad de las Naciones Unidas con arreglo al artículo 39 de la Carta de las Naciones Unidas para "determinar la existencia de cualquier (...) acto de agresión" contraviene lo normado en la Carta de las Naciones Unidas y socava la disuasión (ccPl, s. f. a).
Si bien a nuestro entender esta era una crítica válida, resultaba muy conveniente que proviniera de uno de los miembros permanentes del mencionado Consejo de Seguridad.

Según lo establecido en la Carta de las Naciones Unidas:

Art. 39. El Consejo de Seguridad determinará la existencia de toda amenaza a la paz, quebrantamiento de la paz o acto de agresión y hará recomendaciones o decidirá qué medidas serán tomadas de conformidad con los Artículos 41 y 42 para mantener o restablecer la paz y la seguridad internacional.

Está claro que a fin de intervenir en una situación que amenace o quiebre la paz y la seguridad internacional -las cuales deben ser garantizadas por el Consejo de Seguridad como principal objetivo de la onu - es el Consejo el que debe calificar si un acto constituye o no una agresión de un Estado hacia otro.

Pero la Carta de Naciones Unidas no establece ni tipos penales ni responsabilidades individuales. Esto está fuera de su alcance y excede lo estrictamente regulado por el art. 39. Por ello creemos que es necesario distinguir entre la actuación de la comunidad internacional sobre una situación de agresión que pueda amenazar la paz y la seguridad internacional y la imputabilidad de la responsabilidad penal individual hacia quienes cometieron dichos actos. De no realizarse esta diferenciación, hechos como el bombardeo de un Estado contra un pueblo de otro Estado pueden quedar penalmente impunes si el Consejo de Seguridad no ve en ello un 
acto de agresión porque resulte políticamente inconveniente hacerlo.

Debe haber un control político de toda intervención, y en esto estamos de acuerdo. Pero la aplicación del derecho no puede quedar al arbitrio de las conveniencias políticas de cada momento, ya que ello amenaza con cubrir hechos aberrantes con mantos de impunidad, lo cual resulta, a las claras, tanto jurídica como socialmente inaceptable.

\section{A. La Resolución 6 y la definición del crimen de agresión}

Decíamos que a los fines de enmendar el Estatuto se convocó la sesión plenaria del 11 de junio de 2010 que antes mencionamos. En ella se sancionó la Resolución 6 que define el crimen de agresión, poniendo de este modo fin a un vacío legal importante y a otra de las críticas de mayor peso hacia el Estatuto de Roma.

Dicha resolución se ajusta a lo regulado por los arts. 121 y 123 y por tanto constituye una enmienda al Estatuto de Roma, aplicable a todos los Estados Parte de este. En ella se elimina el párrafo 2 del art. 5 del Estatuto y se agrega un art. 8 bis para establecer el tipo penal del crimen de agresión.

Artículo 8 bis. Crimen de agresión

1. A los efectos del presente Estatuto, una persona comete un "crimen de agresión" cuando, estando en condiciones de controlar o dirigir efectivamente la acción política o militar de un Estado, dicha persona planifica, prepara, inicia o realiza un acto de agresión que por sus características, gravedad y escala constituya una violación manifiesta de la Carta de las Naciones Unidas.

2. A los efectos del párrafo 1, por "acto de agresión" se entenderá el uso de la fuerza armada por un Estado contra la soberanía, la integridad territorial o la independencia política de otro Estado, o en cualquier otra forma incompatible con la Carta de las Naciones Unidas. De conformidad con la resolución 3314 (XXIX) de la Asamblea General de las Naciones Unidas, de 14 de diciembre de 1974, cualquiera de los actos siguientes, independientemente de que haya o no declaración de guerra, se caracterizará como acto de agresión:

El artículo enumera a continuación siete clases de actos que constituyen el tipo penal al que nos referimos:

- La invasión de un Estado por otro;

- El ataque (por fuera de lo establecido en el art. 51 de la Carta de la onu) de fuerzas armadas de un Estado contra otras de otro Estado o contra la población civil de este;

- Toda ocupación militar que derive de los actos anteriores y que implique el uso de la fuerza;

- El bombardeo;

- El bloqueo de puertos o de costas de un Estado;

- La utilización de las fuerzas armadas de un Estado que se encuentren en un Estado extranjero con acuerdo de este pero que exceda las condiciones pactadas entre ambos Estados in- 
cluyendo toda prolongación de la presencia en el territorio extranjero de fuerzas militares de un Estado foráneo;

- La disposición de un territorio propio de un Estado para que otro Estado pueda agredir a un tercero;

- O el envío por parte de un Estado de grupos irregulares (generalmente denominados "paramilitares") o mercenarios que lleven a cabo actos armados contra otro Estado.

Lo primero que debemos destacar es la atribución personal, no a un Estado, que establece el nuevo art. 8 bis del Estatuto de la cPI respecto al crimen de agresión. En este sentido, se separa del tipo de responsabilidad que se puede atribuir de acuerdo con lo normado por la Carta de Naciones Unidas, tema al que ya nos hemos referido, y aborda específicamente las competencias de la Corte Penal Internacional en este punto.

Con ello, entendemos que se da por tierra el argumento antes explicado sobre la posible arrogación de competencias específicamente reservadas al Consejo de Seguridad sobre la definición del acto de agresión, ya que la competencia individual penal y la de intervención política y responsabilidad internacional son diferentes.

Otra cuestión importante se vincula al carácter de la violación del mencionado artículo, la cual debe ser de carácter objetivo, tal como lo establece el art. 46 de la Convención de Viena sobre el Derecho de los Tratados, de 1969. En el siguiente cuadro Elizabeth Salmón (2011, p. 53) señala algunos ejemplos de casos en los que se está ante la comisión o no de un crimen de agresión.

\begin{tabular}{|c|c|c|c|}
\hline $\begin{array}{c}\text { Tipo de acto } \\
\text { coercitivo }\end{array}$ & $\begin{array}{c}\text { ¿Viola el } \\
\text { artículo } \\
24 \text { de la } \\
\text { Carta de } \\
\text { onU? }\end{array}$ & $\begin{array}{l}\text { ¿Constituye } \\
\text { crimen de } \\
\text { agresión } \\
\text { para el DIP? }\end{array}$ & Ejemplo \\
\hline $\begin{array}{l}\text { La } \\
\text { prohibición } \\
\text { total o } \\
\text { casi } \\
\text { total del } \\
\text { comercio } \\
\text { con otro } \\
\text { Estado }\end{array}$ & No & No & $\begin{array}{l}\text { US Cuban } \\
\text { Democracy } \\
\text { Act y US } \\
\text { Sudan } \\
\text { Accountability } \\
\text { \& Divestment } \\
\text { Act }\end{array}$ \\
\hline $\begin{array}{l}\text { Amenaza } \\
\text { del uso de } \\
\text { la fuerza }\end{array}$ & Sí & No & $\begin{array}{l}\text { Un buque de } \\
\text { la guardia } \\
\text { costera } \\
\text { ordena que } \\
\text { una } \\
\text { plataforma } \\
\text { petrolera } \\
\text { abandone un } \\
\text { área } \\
\text { marítima en } \\
\text { disputa o } \\
\text { "las } \\
\text { consecuencias } \\
\text { serían suyas" }\end{array}$ \\
\hline $\begin{array}{l}\text { Uso de } \\
\text { la fuerza } \\
\text { armada } \\
\text { que no } \\
\text { alcanza el } \\
\text { nivel de un } \\
\text { "ataque } \\
\text { armado" }\end{array}$ & Sí & No & $\begin{array}{l}\text { Un "incidente } \\
\text { fronterizo" } \\
\text { que implica un } \\
\text { breve y } \\
\text { forzado cruce } \\
\text { de } \\
\text { frontera } \\
\text { por parte } \\
\text { de algunos } \\
\text { soldados }\end{array}$ \\
\hline
\end{tabular}




\begin{tabular}{|c|c|c|c|}
\hline $\begin{array}{l}\text { Uso de la } \\
\text { fuerza } \\
\text { armada que } \\
\text { no } \\
\text { alcanza el } \\
\text { nivel de } \\
\text { "ataque } \\
\text { armado", } \\
\text { pero } \\
\text { por su } \\
\text { carácter, } \\
\text { gravedad y } \\
\text { escala es } \\
\text { una } \\
\text { violación } \\
\text { manifiesta } \\
\text { de la Carta } \\
\text { de la onu }\end{array}$ & Sí & Sí & $\begin{array}{l}\text { Bloqueo } \\
\text { armado del } \\
\text { puerto } \\
\text { principal de } \\
\text { otro Estado } \\
\text { para } \\
\text { asegurar } \\
\text { concesiones } \\
\text { comerciales }\end{array}$ \\
\hline $\begin{array}{l}\text { Uso de } \\
\text { la fuerza } \\
\text { armada } \\
\text { que } \\
\text { constituye } \\
\text { un } \\
\text { "ataque } \\
\text { armado", } \\
\text { pero por } \\
\text { su carácter, } \\
\text { gravedad y } \\
\text { escala no es } \\
\text { una } \\
\text { violación } \\
\text { manifiesta } \\
\text { de la Carta } \\
\text { de la onu }\end{array}$ & Sí & No & $\begin{array}{l}\text { Un único } \\
\text { ataque aéreo } \\
\text { contra un } \\
\text { buque naval, } \\
\text { causando } \\
\text { muertes } \\
\text { y daños } \\
\text { materiales }\end{array}$ \\
\hline $\begin{array}{l}\text { Uso de la } \\
\text { fuerza } \\
\text { armada que } \\
\text { constituye } \\
\text { un "ataque } \\
\text { armado" y } \\
\text { que por su } \\
\text { carácter, } \\
\text { gravedad y } \\
\text { escala } \\
\text { constituye } \\
\text { una } \\
\text { violación } \\
\text { manifiesta } \\
\text { de la Carta } \\
\text { de la onu }\end{array}$ & Sí & Sí & $\begin{array}{l}\text { La invasión de } \\
\text { un Estado }\end{array}$ \\
\hline
\end{tabular}

\section{DE LA APLICACIÓN DE ALGUNOS PRINCIPIOS DEL DERECHO}

No ha resultado sencilla la tarea de conjugar principios del derecho penal con otros del derecho internacional, básicamente porque ambas ramas del Derecho aplican principios diferentes.

Para el derecho penal la aplicación de una norma sancionada con posterioridad a los hechos que pretenden perseguirse resulta algo inadmisible, dado que contraría abiertamente el referido principio nullum crimen sine praevia lege. Pero esto era algo que en diversos contextos históricos del derecho internacional ya se había hecho: los juicios de Núremberg y de Tokio contra los jerarcas nazis y japoneses por los actos aberrantes cometidos contra judíos y otros pueblos durante la Segunda Guerra Mundial se realizaron sin tener norma previa que castigara dichos actos. Su justificación se basó en que aquellos, por su gravedad, constituían crímenes contra toda la humanidad y no podían quedar impunes, aun cuando se rompiese con principios penales tan básicos como el de la imposibilidad de castigar un delito si no existe ley previa al hecho.

Lo mismo ocurrió con los actos de genocidio llevados a cabo en la ex Yugoslavia y en Ruanda durante la década de los 90: todavía no existía norma previa que contemplase los delitos de lesa humanidad. Sin embargo, el Consejo de Seguridad de la onu hizo una interpretación especial del Capítulo VII de la Carta de las Naciones Unidas, por la cual entendió que tales crímenes 
podían poner en riesgo la paz y la seguridad internacional si no eran ajusticiados. $Y$ así fue que para ambos casos específicos creó dos tribunales penales internacionales que enjuiciaran los crímenes allí cometidos. Ya hablamos también de la prohibición de aplicación de penas por analogía y los problemas que ello podía causar sobre tipos penales abiertos, como el del crimen de agresión.

Otro problema de compatibilidad se ha presentado respecto de la irretroactividad de la ley penal. El Estatuto de Roma establece que la cPI solamente tendrá competencia para castigar los crímenes cometidos con posterioridad a su entrada en vigor. Ello significa que la Corte solamente podrá conocer causas del año 2002 en adelante, pudiendo quedar impunes posibles actos de gravísimas violaciones a los derechos humanos, como los ocurridos en Guatemala, por ejemplo, contra pueblos originarios mayas. ${ }^{4}$

Pero el derecho penal no es el único con principios que dificultan el objetivo último de la Corte, que es aplicar justicia contra los actos de mayor atrocidad en contra de la humanidad. El derecho internacional, pese a que otorga jurisdicción universal a la cPI, se aplica solo a los Estados

4 Se estima, por un informe de la Comisión para el Esclarecimiento Histórico (CEH) de las Naciones Unidas - Guatemala. Memoria del Silencio- que en dicho país se cometieron 669 matanzas, con más de 200000 muertos y más de 45000 desaparecidos a lo largo de un enfrentamiento contra la población civil que duró unos 36 años (19601996). Los militares y paramilitares guatemaltecos fueron quienes, según la onu, cometieron el $80 \%$ de los crímenes. Anualmente se cometieron 6000 asesinatos de los cuales el 98\% han quedado sin castigo, ya que las víctimas, la mayoría indígenas mayas, no se atrevieron ni se atreven a realizar las denuncias correspondientes ni ninguna acción judicial por miedo a posibles represalias contra ellos o sus familiares. que se encuentren obligados por haber ratificado el Estatuto (ccPI, s. f. b).

Uno de los principales problemas del derecho internacional público es tener que lidiar con lo que constituye una suerte de "pecado original": el principio de igualdad jurídica y soberana de los Estados. En el derecho internacional no se reconoce una supranacionalidad, es decir, algo que se encuentre por encima de la voluntad de los Estados que componen la comunidad internacional. Lo que impera es un orden horizontal, una coordinación de Estados, que solamente se quiebra frente a casos como la irrestricta aplicación obligatoria de las resoluciones del Consejo de Seguridad. Pero en el resto de situaciones, como por ejemplo la ratificación de un tratado internacional, nada ni nadie puede forzar a un Estado a hacerlo, y por ende a quedar obligado a lo que este ordene.

Ello ocurre con el Estatuto de Roma: pese a que la aspiración es que sea ratificado por la totalidad de Estados que conforman la comunidad internacional, ninguno está obligado a hacerlo, lo cual provoca ciertos problemas al momento de establecer la cooperación hacia el Tribunal o hacia el Fiscal con miras a posibilitar las investigaciones necesarias para perseguir ciertos crímenes y a sus responsables directos. 


\section{SOBRE LOS DELITOS Y CRÍMENES INTERNACIONALES Y EXIMICIONES PARTICULARES}

Existe bibliografía especializada que diferencia entre los delitos y los crímenes internacionales. Aunque ambos resultan ser ilícitos para el derecho internacional, empero se distinguen en cuanto a su naturaleza jurídica, sus fuentes, su prescripción y su jurisdicción. Los delitos contra el derecho de gentes (delicta iuris gentium) corresponden a conductas como la falsificación de monedas, el tráfico ilegal de estupefacientes o la piratería, todos ellos de origen en el derecho consuetudinario, mientras que los crímenes internacionales son los referidos a crímenes contra la humanidad, son imprescriptibles, su fuente es convencional y poseen el carácter de normas imperativas para el derecho internacional (jus cogens). La competencia de la cPI es sobre estos últimos, reservando la de los delitos internacionales a los Estados o, eventualmente, a tribunales internos internacionalizados. En cuanto a la jurisdicción, la referencia es sobre la llamada jurisdicción penal universal, fundada a partir del caso Lotus (1927) por la Corte Permanente de Justicia Internacional (CPI), aplicable a toda la comunidad internacional cuando se trate de perseguir un delincuente cuyas actividades resultan hostiles a toda la humanidad, por lo que cualquier nación lo puede capturar y castigar (Quiroga y Arredondo, 2012).

Definido el crimen de agresión, no caben ya muchas dudas sobre el ámbito de aplicación de la Corte Penal Internacional. Son cuatro los delitos tipificados e individual la responsabilidad que se asume y se aplica sobre los criminales que los cometen.

Los artículos 6, 7, 8 y 8 bis -gracias a la Resolución 6 de la Asamblea de Estados Parte- definen con alto grado de precisión los cuatro delitos que se contemplan en el Estatuto de Roma.

Sin embargo, han quedado afuera algunos casos que podrían haberse contemplado pero que, por la prohibición de la analogía y el principio de aplicación de los tipos penales, no pueden ser considerados como punibles dentro del marco legal de la cPl.

Un aspecto polémico en cuanto a los menores es la inimputabilidad. El Estatuto de Roma excluye los crímenes perpetrados por menores de dieciocho años (art. 26), algo que se condice con lo contemplado en la Convención Internacional sobre los Derechos del Niño, que califica como tal a toda persona menor de dieciocho años (art. 1).

Sin embargo, se han encontrado casos de escuadrones de menores en guerras civiles premeditadamente reclutados para perpetrar las atrocidades más indecibles a sabiendas de que su edad es un impedimento para cualquier imputación penal. Sin duda se trata de casos muy lamentables, para los cuales aunque existen condenas para quienes los reclutan, al no ser estos los que cometen los delitos no puede imponérseles penas de la gravedad merecida. En cuanto a la edad de imputabilidad, para la comunidad internacional es menor quien no ha 
cumplido aún los dieciocho años y cualquier disposición en contrario estaría abiertamente opuesta a los convenios internacionales existentes sobre la materia.

También se ha excluido el reclutamiento, la utilización y el entrenamiento de mercenarios para la comisión de los delitos tipificados, aunque sí se incluyen a las fuerzas paramilitares dentro del crimen de agresión. Entendemos que estas apreciaciones, aunque por separado no revistan para algunos la gravedad suficiente para que per se sean entendidos como delitos de lesa humanidad, sí constituyen -y en esto pocas dudas caben- agravantes sobre los delitos efectivamente tipificados. Es en este sentido que su consideración dentro del Estatuto de Roma podría ser muy útil.

Sin embargo, la competencia de la cPI es muy estricta en lo referente a la categoría de crímenes internacionales. Los delitos, incluso aqueIlos que implican una grave violación a los DD. HH., solamente quedan remitidos al régimen de responsabilidad de los Estados y no tienen jurisdicción en cuanto a las personas individuales ni jurídicas no estatales. En materia de responsabilidad internacional todavía están pendientes avances que individualicen la responsabilidad de entes no estatales que actúan dentro del escenario internacional.

En este sentido, la incorporación del "nuevo constitucionalismo latinoamericano" es singular, pues otorga derechos a entes como "la naturaleza", que si bien no pueden actuar en su defensa jurídica por motivos obvios, sí puede exigirlos cualquier persona o comunidad frente al Estado. ${ }^{5}$ Si bien una aplicación de estos principios dentro del derecho internacional sería improcedente - puesto que se estaría aplicando derecho local y no internacional-, muchos de los objetivos forman parte de convenios internacionales sobre la protección y el cuidado del medio ambiente, por lo que su inclusión no hubiera resultado un tema ajeno. La dimensión de las catástrofes ecológicas, tal como la sufrida por Ios EE. UU. en sus costas del Golfo de México por el derrame petrolero de la empresa transnacional británica BP, es una prueba fehaciente del tamaño que puede alcanzar la responsabilidad directa de una persona jurídica frente a un tema como este. Si esto ocurre en un hecho sobre posible responsabilidad, qué más notorio sería si se llegara a utilizar este tipo de daños para afectar a grupos de una población determinada. Estos y otros ejemplos pueden probar que muchas veces la línea que divide los delitos de los crimenes internacionales puede ser borrosa.

La óptica mediante la cual se han incluido o tipificado delitos dentro del Estatuto de Roma ha sido restrictiva en cuanto a los crímenes internacionales, excluyendo al resto de las actividades ilícitas para el derecho internacional a la jurisdicción habitual: la de la responsabilidad in-

5 Por ejemplo, la Constitución de la República del Ecuador, sancionada en 2008, establece en su art. 71 que: "La naturaleza o Pacha Mama, donde se reproduce y realiza la vida, tiene derecho a que se respete integramente su existencia y el mantenimiento y regeneración de sus ciclos vitales, estructura, funciones y procesos evolutivos. Toda persona, comunidad, pueblo o nacionalidad podrá exigir a la autoridad pública el cumplimiento de los derechos de la naturaleza. Para aplicar e interpretar estos derechos se observarán los principios establecidos en la Constitución, en lo que proceda. El Estado incentivará a las personas naturales y jurídicas, y a los colectivos, para que protejan la naturaleza, y promoverá el respeto a todos los elementos que forman un ecosistema." 
ternacional, la cual resulta aún insuficiente para cubrir aquella en cabeza de actores no estatales en el ámbito internacional. Este criterio, notable para tribunales como el de Núremberg de 1945-1946 (y cuyas categorías para los delitos imputados sirvieron como fuente de inspiración para los tipos penales del Estatuto de Roma), hoy quizás no resulta ser el más adecuado frente a la compleja gama de actividades delictivas a nivel internacional y sus potenciales consecuencias humanitarias. La tala de la selva amazónica -algo por sus dimensiones impensado hacia mediados de los años 40- hoy es un riesgo cierto que no puede caer sencillamente bajo la responsabilidad del Estado brasileño, puesto que sus consecuencias afectarán al planeta todo. Está claro que la administración de los recursos naturales es algo que debe recaer sobre los Estados en donde estos se encuentren, pero es preciso aplicar un esquema de cooperación internacional ante posibles violaciones, ${ }^{6}$ ya sea por parte de un particular privado o por parte de una autoridad nacional.

$6 \quad$ No existen normas secundarias para estos casos a nivel internacional. Solamente pueden encontrarse algunas normas primarias que obligan a los Estados parte de tratados internacionales a preservar el medio ambiente, pero ante un eventual incumplimiento no hay una norma secundaria que indique qué hacer o cómo penalizar tal violación. $Y$ en caso de haberla, generalmente recae sobre la responsabilidad internacional del Estado, resarcible comúnmente por vía indemnizatoria. La actividad corporativa muchas veces no mide consecuencias al momento de calcular los beneficios de la actividad lucrativa, y eventualmente es incluida dentro de los costos de la inversión. Es posible que, incluyendo responsabilidades penales individuales en el marco de un sistema de cooperación internacional, sea más difícil sortear las posibles corruptelas de los derechos locales. Pero para ello resulta evidente hacer un llamado a fortalecer una real independencia de la cPI y de su Fiscalía en cuanto al ejercicio de sus investigaciones, a fin de evitar que estas puedan ser suspendidas por el Consejo de Seguridad ante casos en que sean empresas transnacionales de los países desarrollados - que poseen banca permanente en el Consejo- las investigadas por delitos de la gravedad tipificada en el Estatuto de Roma.
El colonialismo u otras formas de dominación extranjera no son punibles dentro del derecho internacional penal. Aun siendo políticamente desdeñable, aun cuando la conquista ya no es reconocida como una forma válida de adquisición de dominios territoriales, aun cuando el uso de la fuerza está jurídicamente prohibido para el derecho internacional público, la dominación colonial no configura delito.

La Resolución 1514/60 de la Asamblea General declara que la dominación y explotación extranjeras constituyen una denegación de los derechos humanos fundamentales, que es contraria a la Carta de las Naciones Unidas y además compromete la causa de la paz y la cooperación mundiales; que todos los pueblos tienen derecho a la libre determinación, y en virtud de este a establecer libremente su condición política y a perseguir su desarrollo económico, social y cultural. Con esta resolución se procedió definitivamente a la independencia de casi todas las colonias europeas en África y Asia, quedando no obstante algunos pocos puntos bajo el dominio colonial hasta hoy.

La resolución que nos ocupa se dio en un doble contexto histórico: el de la creación de nuevos mercados para las potencias occidentales, y el de la multiplicación, por centenares, de agrupaciones clandestinas que optaron por la lucha armada como método para acceder a la denominada "liberación nacional" de las potencias coloniales. Hoy el contexto es otro, y sin embargo la dominación colonial todavía no constituye un delito penalmente reprochable a nivel internacional. 


\section{EL PROCESO DE ENMIENDAS AL ESTATUTO DE ROMA: LA CONFERENCIA DE KAMPALA (2010)}

En Kampala (Uganda), entre los días 31 de mayo y 11 de junio de 2010, los Estados Partes del Estatuto de Roma discutieron sobre tres propuestas de reforma: la revisión del art. 124, la definición del crimen de agresión y la inclusión del uso de ciertas armas como crimen de guerra, en el contexto de un conflicto armado que no sea de carácter internacional. Asimismo, se realizó una evaluación del desarrollo de la cPI y del Estatuto ya en vigor. Todo esto lo habría de hacer la Asamblea de Estados Partes (AEP), instituida según el art. 112 del Estatuto.

El proceso de evaluación (stocktaking) implicó un esfuerzo previo en los trabajos de preparación de la Conferencia, tareas que fueron asumidas por varios Estados miembros así como por algunas ONG - como la Coalición por la Corte Penal Internacional (ccPI) y la Human Rights Watch (HRW)-. La evaluación se realizó sobre la complementariedad de la Corte (a cargo de Dinamarca y Sudáfrica), la cooperación (a cargo de Irlanda y Costa Rica), el impacto del sistema del Estatuto de Roma sobre las víctimas y las comunidades afectadas (Chile y Finlandia) y la necesidad de equilibrar el intento de la cPI de alcanzar sus objetivos de paz y justicia (Argentina, República Democrática del Congo y Suiza) (ccPl, s. f. b).

Tanto los organismos del sistema onu como la mayoría de los Estados que componen la co- munidad internacional están de acuerdo en que no puede existir una paz duradera sin justicia y que, por ende, ambas ideas tienen una correlación directa. Un punto importante en la evaluación de la cPI fue la necesidad de lograr equilibrio en el intento de la Corte de alcanzar sus objetivos de paz y justicia. La relación entre ambos conceptos, tal como fue señalado en el Preámbulo del Estatuto de Roma y en el sistema de la onu, así como la importancia de la futura eficacia de la cPI como elemento fundamental de paz, muestran la gama de desafíos que los procesos de verdad deben atravesar como requisitos indispensables para la reconciliación y como complementos de la justicia penal y la defensa de los intereses de las víctimas.

La cooperación también fue un tema relevante en la Conferencia de Kampala. En este sentido se evidenció la necesidad de incentivar un mayor grado de cooperación entre los Estados miembros y no miembros del Estatuto como modo indispensable para alcanzar los objetivos buscados, incluyendo también a organizaciones de la sociedad civil en el proceso.

Por último, respecto al impacto sobre las víctimas y las comunidades afectadas, se realizaron análisis interesantes sobre la sensibilización y la importancia de reconocer los derechos de las víctimas a la justicia, la participación y la reparación, especialmente en los países con situaciones delicadas y, en términos concretos, una revisión de cómo el Fondo Fiduciario en Beneficio de las Víctimas ha contribuido con la dignidad individual, la curación y la rehabilitación de estas. También se habló sobre la necesidad de 
asumir mayores compromisos para contribuir con el Fondo Fiduciario; adoptar legislaciones nacionales para las víctimas y las comunidades afectadas en pro de su preparación y la búsqueda de verdad y justicia; o -eventualmente- obtener compromisos mediante acuerdos ad hoc con la Corte en relación con las víctimas y las comunidades afectadas.

El objetivo de quienes hicieron el Estatuto de Roma no fue crear una Corte que funcionara como un simple aparato burocrático, sino un sistema de justicia internacional general en materia penal donde se viera claramente reforzado el deber de los Estados Partes de investigar y procesar los crímenes internacionales (ccPl, s. f. b). Para ello, la complementariedad debía ser un principio fundamental dentro de esta estructura, siendo la CPI una Corte de "último recurso" pero no de superior rango a las supremas Cortes nacionales -algo que suscitó no poca polémica-, y que solo se involucrara cuando las jurisdicciones nacionales no hubieran acabado debidamente con los crímenes internacionales que cuadren en sus tipos penales.

Por ende, la AEP emitió un informe sobre la evaluación de la complementariedad junto con una resolución borrador para el análisis de la Conferencia de Revisión, en el que se hicieron varias recomendaciones: a) que los Estados Partes reafirmen que las jurisdicciones nacionales tienen la responsabilidad primaria de juzgar los delitos; b) que los Estados y la Corte, entre otros actores, fortalezcan el principio de complementariedad alentando los procedimientos nacionales cuando sea necesario, como un modo de terminar con la impunidad; c) que los Estados Partes consideren la necesidad de tomar nuevas medidas a nivel nacional para combatir la impunidad $y$, en coordinación con la Corte, examinen modos para que la jurisdicciones nacionales sean capaces de lidiar con los crímenes más terribles, con el fin de no atosigar a la CPI con causas que conviertan el sistema en una burocracia ineficiente; d) que la Asamblea establezca facilidades para el intercambio de información para fortalecer las jurisdicciones nacionales.

También se resaltó la importancia de recabar y examinar las experiencias de los Estados Partes a la hora de ejercitar sus jurisdicciones nacionales para lidiar con los crímenes establecidos en el Estatuto de Roma, destacando la legislación vigente utilizada y el tipo de proceso que se siguió con el fin de crear un marco de referencia para fortalecer la participación. Pero también es preciso analizar la intención o la falta de ella por parte de los Estados miembros a la hora de utilizar las Cortes nacionales para juzgar los crímenes internacionales. Es de todo este material que la AEP se ha valido para analizar la aplicación del derecho internacional penal en lo que constituye, todavía hoy, un ejemplo del desarrollo progresivo del derecho internacional público.

Así, el informe mostró un buen avance, pero parcial, en cuanto al cumplimiento de los objetivos de la cPI, tema que justificaba además el proceso de enmiendas que era entendido como necesario.

En cuanto a los puntos de reforma, la Conferencia completó su trabajo parcialmente. Uno de 
los temas iniciados fue la reforma del art. 124, que permite que un Estado al momento de ratificar o adherir al Estatuto de Roma pueda declarar unilateralmente que por un período de siete años no se le aplique la jurisdicción de la cPI. Algunas organizaciones sociales recordaron que oportunamente se manifestaron rotundamente en contra de la inclusión de esta cláusula en el tratado (ccPI, s. f. b). Solo dos Estados utilizaron este artículo: Francia y Colombia, aunque el primero retiró su declaración en 2008 , dejando a Colombia como el único miembro bajo la excepcionalidad del art. 124, cuyos efectos expiraron el $1^{\circ}$ de noviembre de 2009.

Bélgica propuso modificar el art. 8 para extender la criminalización del uso de armas biológicas, veneno, armas envenenadas, gases asfixiantes, tóxicos o similares o cualquier líquido, material o dispositivo análogo, así como también el uso de balas que se ensanchen o se aplasten fácilmente dentro del cuerpo humano. El uso de las armas enumeradas en esta propuesta de reforma ya estaban penalizadas por el artículo 8, párrafo 2 b, numerales xvii al xix del Estatuto pero para el caso de un conflicto armado internacional, no de conflictos no internacionales. México también propuso agregar el uso de armas nucleares a la definición de crimen de guerra.

En cuanto a la definición del crimen de agresión, basta con lo ya expuesto anteriormente y que resultó en la Resolución 6 de la AEP.

Lo último del proceso de reforma -y por ello es que se trata de un proceso- es que la AEP decidió conformar un Grupo de Trabajo sobre las enmiendas. Asimismo, al ser la CPI una organización independiente pero dentro del Sistema de Naciones Unidas, existe un grado de complejidad que las delegaciones reconocieron en cuanto a la posible superposición de áreas y funciones sobre ciertas definiciones jurídicas. ${ }^{7}$ Todos estos temas fueron abiertos en Kampala sin que se hayan producido decisiones definitivas hasta el momento.

Por ello es que el proceso de reforma debe contar con un seguimiento participativo de la sociedad civil -en su concepto más amplio, tanto de ong como de movimientos sociales-, ya que se trata de temas abiertos que seguramente no son ajenos a las tensiones entre los distintos intereses políticos, entre Estados y entre sectores sociales. $Y$ donde se juegan intereses, existe la política como fuente material de derecho que habrá de servir de escenario para lo que luego quede definido como el "encuadre jurídico".

\section{ALGUNOS CASOS DE POSIBLE APLICACIÓN DEL ESTATUTO DE LA CPI}

En el trabajo de la Corte se diferencia lo que son llamadas "situaciones", de las causas penales en sí. Una "situación" es aquella en la que la Fiscalía o la misma Corte se han alertado y están

7 Por ejemplo, el acto de agresión ya había sido definido por la Asamblea General de la onu en la Resolución 3314 (XXIX). Del mismo modo, la definición de los crímenes de guerra está contenida dentro de los Convenios de Ginebra de 1949 del cıcr. La complejidad está dada en que este tipo de definiciones se aplican a lo que es la responsabilidad internacional de los Estados, pero no tiene competencia alguna sobre los individuos. Por otra parte, los Estados parte de estos distintos instrumentos internacionales no necesariamente pueden ser parte también del Estatuto de Roma, con lo que podrían encontrarse distintos ámbitos de aplicación sobre una posible superposición de funciones. 
haciendo un seguimiento basándose en la posibilidad de que en ese lugar o por las acciones que se están desarrollando pueda haber una posible acusación en el futuro cercano. En estos momentos se han abierto veintiún casos dentro de ocho situaciones bajo jurisdicción de la CPI: Congo, República Centroafricana, Uganda, Darfur (en Sudán), Kenia y las nuevas situaciones desarrolladas en Libia, Costa de Marfil y Malí.

La CPI tiene en total veintiuna causas iniciadas sin que todavía haya ninguna resuelta. Las primeras causas iniciadas datan del año 2004, dos años después de la entrada en vigencia del Estatuto de Roma. Cinco casos corresponden al conflicto en la República Democrática del Congo y otra más corresponde a Uganda, todas ellas en etapa de investigación. En 2005 se iniciaron otras cinco causas: una correspondiente a la situación en la República Centroafricana y las cuatro restantes a la de Darfur. Se hallan en etapa prejudicial -es decir incluso previo a la investigación del Fiscal- las situaciones de Kenia, con hechos abiertos en 2009; la de Libia, abierta a partir de 2010 con la "Primavera Árabe" y las represiones ocurridas por el régimen de Muammar Qadhafi; y los sucesos transcurridos a partir de 2011 en Costa de Marfil que finalmente originaron la intervención francesa en 2013. El último caso abierto fue en enero de 2013 sobre los crímenes de guerra en el norte de Malí, a raíz de la guerra civil iniciada en 2012 (cPI, s. f. b).

Como puede observarse, hasta el momento todos los procesos que se han abierto y todas las situaciones analizadas por la cPI están situados en el continente africano. Son casos terribles, sin duda, pero existen realidades más allá del África que deberían también requerir la atención de la Corte, puesto que el terror del poder y los horrores de estos tipos de crímenes no son exclusividad del continente más empobrecido de la Tierra. Existen delitos continuados en otras latitudes del globo así como otros actos que la Corte también debería considerar dentro del proceso de reforma de su Estatuto para que sean incluidos.

\section{A. Posible aplicación del estoppel para Estados no miembros de la CPI a raíz de la situación en Libia (2011)}

El Consejo de Seguridad de Naciones Unidas, el 26 de febrero de 2011 aprobó la Resolución 1970 en la que tomó medidas sobre la preocupante situación en Libia. Posteriormente, el 17 de marzo de 2011, emitió la Resolución 1973, en que incrementa las medidas tomadas y adopta otras nuevas de mayor peso, considerando que los sucesos en dicho país fueron agravándose.

Notorios han sido los hechos desatados en casi la totalidad de los países del mundo árabe, en donde han venido produciéndose manifestaciones sociales en reclamo por una apertura democrática de los regímenes imperantes tanto en los países de Medio Oriente como del Magreb. Dichas manifestaciones no tienen el mismo trasfondo social y político (algunas se sitúan en un contexto de reclamos desde distintas vertientes del islamismo - chítas vs. sunitas- mientras que otras son protestas laicas) y en cada país han tenido resultados igualmente 
distintos. Mientras que en Jordania o en Siria la movilización popular forzó a reformas importantes por parte de los regímenes monárquicos imperantes que de ese modo garantizaron su continuidad, en Túnez o Egipto provocaron revoluciones que acabaron por reemplazar ambos regímenes.

Distinta fue la situación en Libia en 2010, donde las manifestaciones y movilizaciones sintieron la represión más feroz por parte del régimen de Muammar Qadhafi, quien ordenó el ataque directo contra poblaciones civiles a fin de amedrentar a los manifestantes. Las víctimas fatales de esta condenable y flagrante represión contra la propia población civil se cuantificaron en miles, lo cual motivó una fuerte preocupación por parte de la comunidad internacional.

Empero, a la crisis humanitaria creada por el gobierno contra su pueblo se suman motivos económicos que resaltan distintos intereses en juego y que motivan que este caso en particular merezca una atención por parte de la comunidad internacional -principalmente por las potencias centrales- que otros como los de Egipto, Túnez, Bahréin, Qatar, Argelia, Jordania, Siria - por citar algunos-, no han merecido. Y dichos motivos radican en que Libia es el principal productor de petróleo de los países del Magreb, y uno de los mayores proveedores de crudo de la Unión Europea (UE), con un producto que es de excelente calidad por su poca necesidad de destilación para convertirlo a combustible (algo muy distinto de lo que ocurre con crudo proveniente de, por ejemplo, Venezuela).
A pesar de que la Resolución más resonante ha sido la 1973, por la cual -entre otras medidasse declara el espacio de exclusión aérea sobre Libia y se autoriza a los miembros de las Naciones Unidas a que "en cooperación con el Secretario General, adopten todas las medidas necesarias, (...) para proteger la vida de los civiles y las zonas pobladas por los civiles que estén bajo amenaza de ataque" por parte del gobierno libio, queremos resaltar aquí algo quizás no destacado en la anterior Resolución del Consejo de Seguridad, la 1970, y que hace alusión al tema que nos convoca: la decisión por parte de este organismo de la onu de "remitir la situación imperante en la Jamahiriya Árabe Libia desde el 15 de febrero de 2011 al Fiscal de la Corte Penal Internacional", y aunque reconoce que "los Estados que no son parte del Estatuto de Roma no tienen obligación alguna en virtud de él, insta a todos los Estados y organizaciones regionales y demás organizaciones internacionales competentes a que cooperen plenamente con la Corte y el Fiscal".

Estos párrafos de la Resolución 1970 no serían de mayor relevancia si esta no hubiera sido adoptada por unanimidad, sin abstenciones, por todos los que en este caso conformaron el Consejo de Seguridad: Estados Unidos (no miembro de la cPI), Rusia (no miembro de la Corte), China (tampoco miembro de la Corte), India (tampoco miembro de la Corte) y Líbano (único país árabe actualmente en el Consejo y tampoco miembro de la Corte), además de los otros miembros de la actual composición: Francia, Alemania, Sudáfrica, Gabón (que ratificaron el Estatuto de Roma en el año 2000), Reino Unido, 
Nigeria (que lo hizo en 2001), Bosnia y Herzegovina, Brasil, Colombia y Portugal (que por su parte lo hicieron en 2002).

Al ser las resoluciones del Consejo de Seguridad instrumentos jurídicos de carácter vinculante para toda la comunidad de Estados, la obligación que este órgano impone de cooperar con la CPI y con su Fiscal a toda la comunidad internacional, haya o no ratificado el Estatuto de la Corte, resulta obligatoria para los Estados. Pero también hay una cuestión de importancia, máxime cuando es una decisión que cuenta con la aprobación de Estados no miembros de la cP: entendemos que sería aplicable la teoría del estoppel en cuanto a la responsabilidad que le cabe a aquellos Estados que han aprobado tal resolución autoimponiéndose obligaciones de cooperación para con la cPl, aun siendo Estados no miembros. Este caso puede significar un antecedente de importancia para avanzar en un mayor compromiso hacia la cPI.

\section{A MODO DE CONCLUSIÓN: ALGUNOS APORTES TEÓRICOS CRÍTICOS SOBRE LOS CRÍMENES DE MASA}

Como hemos analizado en el presente trabajo, se evidencia una relación conflictiva entre el comportamiento de algunos Estados (especialmente en el caso de EE. UU.) respecto de la cPI, a punto tal de generar normativa interna que resulta incompatible con el desempeño de dicha institución. Ello ha significado un fuerte intento de limitar la competencia de la Corte en casos concretos que pudieran afectar los intereses norteamericanos en sus intervenciones militares. De hecho, hasta la fecha los enjuiciamientos en curso por parte de la cPI tratan básicamente de casos ocurridos en países africanos y contra acusados que detentan nacionalidades de dichos países, evitando iniciar investigaciones que puedan interferir con los intereses de los miembros permanentes del Consejo de Seguridad de la onu. Tal situación, a su vez, se refleja en una fuerte restricción del Estatuto de Roma a la Fiscalía en cuanto a sus facultades de investigación -punto que no se pudo avanzar en este trabajo-, labores que pueden ser suspendidas por decisión del Consejo de Seguridad por un plazo de doce meses prorrogables. ${ }^{8}$

Sin embargo, la CPI ha logrado superar ciertos obstáculos que constituían graves "pecados de nacimiento" de la organización, tales como la definición de agresión en su tipología o la situación de suspensiones excepcionales unilaterales a la aplicación de la jurisdicción de la Corte (art. 124 del Estatuto de Roma), cuestiones que debían caer por su propio peso pero que sin embargo en 1998 no lograron el consenso necesario para ello.

Todo lo dicho no obsta para que los denominados "crímenes de masa" dejen de acaecer, dado que -aun cuando no existiesen las dificultades políticas mencionadas con algunos Estados protagónicos del escenario internacional- estos

8 Según el art. 16 del Estatuto de Roma, para que esta suspensión proceda la solicitud debe emanar del Consejo de Seguridad de la onu, mediante resolución aprobada en aplicación del Capítulo VII de la Carta de Naciones Unidas. 
suponen elementos que les son característicos y que se vinculan con una situación de poder frente a otros. Hay una idea central en cuanto a la comisión de los crímenes de masa -aberraciones contra las que básicamente luchan instituciones como la $\mathrm{CPI}-\mathrm{y}$ es que los principales son cometidos desde la propia estructura del aparato estatal (Zaffaroni, 2010) o apoyados por este mediante aparatos paraestatales. Ello básicamente ocurre por la pretenciosa sensación de impunidad que se arraiga en la naturaleza misma del poder. Es la falsa -pero no por ello pretendida-idea de sentirse intocable, más allá de toda ley y todo derecho, en que cae quien detenta el poder, en la figura de aquel que posee el control y la posibilidad real de ejercer toda la potencialidad de su autoridad frente a un "otro". En otras palabras, el que está en una posición de autoridad no siente encontrarse por debajo de nada ni nadie, lo cual le produce una sensación de superioridad que el Derecho no puede explicar por sus procedimientos científicos: ${ }^{9}$

La esencia del carácter autoritario ha sido descrita como la presencia simultánea de

9 Cuando una disciplina científica (como es el Derecho) choca con sus límites epistémicos es cuando debemos recurrir al conocimiento de otras que aporten a un enfoque interdisciplinario a fin de resolver los problemas de investigación a los que nos estemos enfrentando. De otro modo, estaremos dogmatizando el conocimiento disciplinar. Es decir que, frente a los problemas actuales del Derecho que el propio Derecho no puede resolver, es necesario nuestro acercamiento a otras áreas del conocimiento científico. En el tema que nos ocupa, el Derecho no puede explicar el porqué de la reiteración de estos crímenes, para lo cual decidimos tomar elementos de la psicología que expliquen el sentido de estos comportamientos. Así es como encontramos, dentro del psicoanálisis, dos vertientes que Freud separó siempre con sumo cuidado: la vertiente terapéutica, destinada a la curación de las neurosis y que conlleva a una metodología y una teoría psicológicas; y la vertiente filosófica que comprende sus hipótesis más ambiciosas como tentativas de un análisis de la cultura. Esta última vertiente suele denominarse "metapsicología freudiana" y tiene su puntapié inicial en el famoso escrito El malestar en la cultura (1929), además de obras como Más allá del principio del placer (1920) del citado autor austríaco. tendencias impulsivas sádicas y masoquistas. El sadismo fue entendido como un impulso dirigido al ejercicio de un poder ilimitado sobre otra persona, y teñido de destructividad en un grado más o menos intenso; el masoquismo, en cambio, como un impulso dirigido a la disolución del propio yo en un poder omnipotente, para participar así de su gloria. Tanto las tendencias masoquistas como las sádicas son debidas a la incapacidad del individuo aislado de sostenerse por sí solo [y así] superar esta soledad (Fromm, 1993, p. 214)

Ese "anhelo sádico del poder" forma parte de la racionalización del sadismo que se expresa dentro del aparato del Estado en su manifestación más destacada: el Estado autocrático. Mas el poder actúa dentro de una lógica que se circunscribe en el orden sistémico en que se encuentra: el poder pretende acumular más poder.

Es evidente que la comisión de estos crímenes aberrantes pone al Derecho en un dilema no solo sobre la obligatoriedad de la norma, sino además sobre la consecuencia jurídica de la aberración: ¿cómo castigar a lo más atroz de modo que eso no vuelva a suceder? Y además ¿cómo es que, sin embargo, estos hechos se reiteran y cómo hacer entonces para que el Derecho no se convierta en una herramienta inútil frente a estos crímenes, dado que parece ser incapaz de evitar su repetición?

Debemos desterrar la hipótesis punitiva del castigo. Reprimir al genocida no es suficiente para regular las acciones humanas, que es el último objetivo del Derecho. Pero lo complejo del tema 
de los crímenes de masa es que, a lo que se pretende reprimir es precisamente al poder mismo, que es quien reprime. Es decir, cuando el poder punitivo del Estado se "descontrola" desaparece el Estado de derecho y su lugar lo ocupa el de policía. Se trata, pues, de limitar al poder en su versión más atroz: la de la violencia desatada en contra de súbditos suyos o extranjeros. La legitimidad de establecer organismos como la CPI radica en evitar caer en lo que sería un "derecho del enemigo", en el cual se castiga por el simple hecho de ser "otro" que detentó, usó y abusó de su poder sin que se lo reconozca como par. Si queremos evitar aplicar el derecho del enemigo, es menester reconocerle al autor del crimen el carácter de persona y ser juzgada por el acto que ha cometido (Zaffaroni, 2010).

A pesar de ello, esa limitación del poder encuentra dificultades dadas por el propio derecho internacional: el hecho de que nada se encuentra por encima de la soberanía de los Estados y que solamente ellos sean los que pueden acceder a cualquier limitación en el despliegue de su poder (como ser sometidos a la jurisdicción de la Corte, por ejemplo), no quita que debamos resignar nuestras expectativas de transformación. Los avances en el proceso de enmienda del Estatuto de Roma muestran que las reformas pueden servir, aun cuando se trate de dar sucesivos pasos hacia completar los objetivos originales de aquellos que idearon la Corte Penal Internacional. Pero debemos reconocer también que la modificación del Estatuto no evitará la comisión de esta clase de crímenes, cuyo análisis debe incluir dimensiones sociales, psicológicas, políticas y económicas, además de las jurídicas. Es por ello que la existencia de la cPI es algo necesario y saludable, pero siempre insuficiente.

El principal aporte crítico es, entonces, el desafío de poder abordar los problemas jurídicos con una actitud activa y desde una perspectiva interdisciplinaria (que lamentablemente no hemos podido cubrir en este trabajo), para así dimensionar mejor los propios límites de la ciencia del Derecho; no por criticar esta, nuestra disciplina, sino para tratar los problemas con una batería más compleja y más adecuada de herramientas que logren contener al poder. Esa es, en definitiva, la mejor solución con la que contamos para luchar en este presente contra los crímenes internacionales: no solo punir los actos, sino controlar al poder.

\section{Referencias}

Amnistía Internacional. (11 de noviembre de 2007). Estados Unidos y la Corte Penal Internacional. Recuperado en enero de 2014 de: https://www.amnesty.org/es/campaigns/usa-andinternational-criminal-court.

Asamblea General de la onu. (14 de diciembre de 1974). Resolución 3314 (XXIX). Recuperado en marzo de 2011, de ods: http://daccessdds-ny.un.org/doc/RESOLUTION/GEN/NRO/743/93/ IMG/NR074393.pdf?OpenElement

Coalición por la Corte Penal Internacional -ccPI. (s. f. a). EE. UU. y la Corte Penal Internacional. Recuperado en marzo de 2011, de: http:// www.iccnow.org/?mod=usaicc\&lang=es 
Coalición por la Corte Penal Internacional -CCP. (s. f. b). Cumpliendo con la promesa de una Corte efectiva, justa e independiente. Conferencia de Revisión del Estatuto de Roma. Recuperado en marzo de 2011, de: http://www. iccnow.org/?mod=review\&lang=es

Consejo de Seguridad de las Naciones Unidas. (2011a). Resolución 1970 del 26/02/2011.

Consejo de Seguridad de las Naciones Unidas. (2011b). Resolución 1973 del 17/03/2011.

Consejo Nacional de las Mujeres. (2008). Constitución de la República de Ecuador. Quito: Consejo Nacional de las Mujeres.

Corte Penal Internacional. (s. f. a). Lista de Estados Partes de la Corte Penal Internacional. Recuperado en enero de 2014, de: http:// www.icc-cpi.int/en_menus/asp/states\%20parties/ Pages/the\%20states\%20parties\%20to\%20the\%20 rome\%20statute.aspx\#

Corte Penal Internacional. (s. f. b). Situations and cases. Recuperado en abril de 2011, de: http:// www.icc-cpi.int/Menus/ICC/Situations+and+Cases/

Corte Penal Internacional. (1998). Estatuto de Roma de la Corte Penal Internacional. En Compendio de Normas internacionales. Buenos Aires: La Ley.

Corte Penal Internacional. (11 de junio de 2010). Resolución RC/Res.6. El crimen de agresión. Recuperado de: http://www.icc-cpi.int/iccdocs/ asp_docs/Resolutions/RC-Res.6-SPA.pdf
Corte Penal Internacional. (2011). Review Conference of the Rome Statute. Recuperado en marzo de 2011, de: http://www.icc-cpi.int/NetApp/App/MCMSTemplates/Content.aspx?NRMODE $=$ Published\&NRNODEGUID $=\{$ 10B31AA2-326E-498BB270-5924F98D7937\}\&NRORIGINALURL=/Menus/ ASP/ReviewConference/Review+Conference.htm\&N RCACHEHINT=Guest\# officialdoc

Corte Penal Internacional. (2014). News and Highlights. Recuperado en enero de 2014, de: http://www.icc-cpi.int/EN_Menus/icc/Pages/default.aspx

Departamento de Estado de los EE. UU. (2003). Posición oficial de los EE. UU. sobre la Corte Penal Internacional. Recuperado en marzo de 2011, de: http://www.state.gov/t/pm/rls/othr/ misc/23425.htm

Fromm, E. (1993). Psicología del nazismo. En El miedo a la libertad. Buenos Aires: Planeta Agostini.

Falca, M. y Martínez Soto, D. (18 de abril de 2004). Estados Unidos solicitó a Uruguay alojar a personal norteamericano destinado en Irak. Obtenido de: http://www.Ir21.com. uy/politica/138927-estados-unidos-solicitoa-uruguay-alojar-a-personal-norteamericanodestinado-en-irak

Quiroga, T. y Arredondo, R. (2012). La responsabilidad penal individual. En R. Arredondo, Manual de Derecho Internacional Público. Buenos Aires: La Ley. 
Salmón, E. (2011). El crimen de agresión des- Zaffaroni, E. R. (2010). Crímenes de masa. pués de Kampala: soberanía de los estados y lucha contra la impunidad. Lima: Instituto de Buenos Aires: Ediciones Madres de Plaza de Mayo.

Democracia y Derechos Humanos de la Pontificia Universidad Católica de Perú. 